\title{
Synaptic Enhancement and Enhanced Excitability in Presynaptic and Postsynaptic Neurons in the Conditioned Stimulus Pathway of Hermissenda
}

\author{
R. J. Frysztak and T. Crow \\ Department of Neurobiology and Anatomy, University of Texas Medical School, Houston, Texas 77225
}

\begin{abstract}
Identified type A photoreceptors of Hermissenda express differential effects of classical conditioning. Lateral type A photoreceptors exhibit an increase in excitability to both the conditioned stimulus (CS; light) and extrinsic current. In contrast, medial type A photoreceptors do not express enhanced excitability, but do show enhancement of the medial B to medial A synaptic connection. Therefore, both enhanced excitability and changes in synaptic strength may contribute to long-term plasticity underlying classical conditioning. The activation of protein kinase $C(P K C)$ is involved in the induction of enhanced excitability of identified type $B$ photoreceptors produced by one-trial conditioning and the expression of enhanced excitability in $B$ photoreceptors after multitrial classical conditioning. We have examined a possible role for persistent kinase activity in the expression of enhanced excitability in lateral type A photoreceptors and enhancement of the medial B to medial type A synaptic connection after classical conditioning. Injection of the PKC inhibitor peptide PKC(19-36) into medial type B photore-
\end{abstract}

ceptors of conditioned animals did not significantly change the amplitude of medial A IPSPs elicited by single spikes in the medial B photoreceptor. Injections of PKC(19-36) into medial B photoreceptors of pseudorandom controls also did not significantly change the amplitude of IPSPs recorded from the medial A photoreceptor. In contrast, spikes elicited by extrinsic current in lateral type A photoreceptors of conditioned animals were significantly reduced in frequency after intracellular injection of PKC(19-36) as compared with pseudorandom controls. Injection of the noninhibitory analog peptide $\left[g^{2}{ }^{27}\right] \mathrm{PKC}(19-36)$ did not affect excitability. Thus, enhanced excitability in the lateral A photoreceptor of conditioned animals seems to be influenced, in part, by a constitutively active kinase or a persistent kinase activator, whereas synaptic enhancement of the connection between the medial B and medial A photoreceptors of conditioned animals may involve a different mechanism.

Key words: Hermissenda; synaptic enhancement; enhanced excitability; classical conditioning; associative learning; facilitation
Cellular neurophysiological studies of identified neurons in several invertebrate preparations have revealed examples of plasticity that are expressed by modifications of neuronal excitability and alterations in synaptic strength (for review, see Carew and Sahley, 1986; Crow, 1988; Byrne and Crow, 1995). In conditioned Hermissenda, enhanced excitability and synaptic enhancement have been identified as cellular correlates of associative learning in the pathway supporting the conditioned stimulus (CS) (Crow and Alkon, 1980; Farley and Alkon, 1982; Alkon et al., 1985; Frysztak and Crow, 1993, 1994). Enhanced excitability in identified neurons of conditioned Hermissenda is expressed by increases in spike frequency elicited by extrinsic current, an increase in the input resistance of type B photoreceptors, decreased spike frequency accommodation, an alteration in the amplitude of light-induced generator potentials, and a decrease in several $\mathrm{K}^{+}$conductances (Crow and Alkon, 1980; Alkon et al., 1982, 1985; Farley and Alkon, 1982; West et al., 1982; Crow, 1985; Farley et al., 1990; Frysztak and Crow, 1993). In addition to the nonsynaptic enhancement in excitability detected after conditioning, enhancement of the amplitude of monosynaptic IPSPs has been observed

Received Nov. 14, 1996; revised March 14, 1997; accepted March 17, 1997.

This work was supported by National Research Service Award MH10326 (R.J.F.) and National Institute of Mental Health Grants MH40860 and MH01363 (T.C.)

Correspondence should be addressed to Dr. T. Crow, Department of Neurobiology and Anatomy, University of Texas Medical School, Houston, TX 77225.

Dr. Frysztak's present address: Department of Physiology, National College of Chiropractic, Lombard, IL 60148.

Copyright (C) 1997 Society for Neuroscience $\quad 0270-6474 / 97 / 174426-08 \$ 05.00 / 0$ in conditioned Hermissenda (Frysztak and Crow, 1994). Moreover, 5-HT and GABA, two putative neurotransmitters in the unconditioned stimulus (US) pathway, have been reported to produce enhancement of type B to type A photoreceptor synaptic connections (Schuman and Clark, 1994; Schultz and Clark, 1995). Secondmessenger pathways mediating the effects of 5-HT and GABA on enhanced excitability and synaptic enhancement have been studied recently (Matzel et al., 1990; Crow et al., 1991; Crow and Forrester, 1993; Yamoah and Crow, 1996). Protein kinase C (PKC) is involved in the induction of enhanced excitability produced by one-trial conditioning, 5-HT-induced synaptic enhancement, and the expression of enhanced excitability in type B photoreceptors produced by multitrial Pavlovian conditioning (Neary et al., 1986; Matzel et al., 1990; Crow et al., 1991; Farley and Schuman, 1991; Schuman and Clark, 1994). In this report, we have examined the potential role of persistent PKC activity in the expression of enhanced excitability of lateral type A photoreceptors and the enhancement of the medial type B to medial type A synaptic connection of conditioned Hermissenda. We report that the injection of the PKC inhibitory peptide PKC(19-36) into the medial type B photoreceptor of conditioned animals did not reverse the enhancement of IPSP amplitude produced by conditioning. PKC(19-36), however, did block the induction of synaptic enhancement of the same identified connections produced by the bath application of 5-HT. In contrast to the insensitivity of synaptic enhancement to the kinase inhibitor, enhanced excitability in lateral type A photoreceptors of conditioned animals was reversed by PKC(19-36). The noninhibitory peptide $\left[\mathrm{glu}^{27}\right] \mathrm{PKC}(19-36)$ did not reverse the enhanced excitability produced by conditioning in lateral 


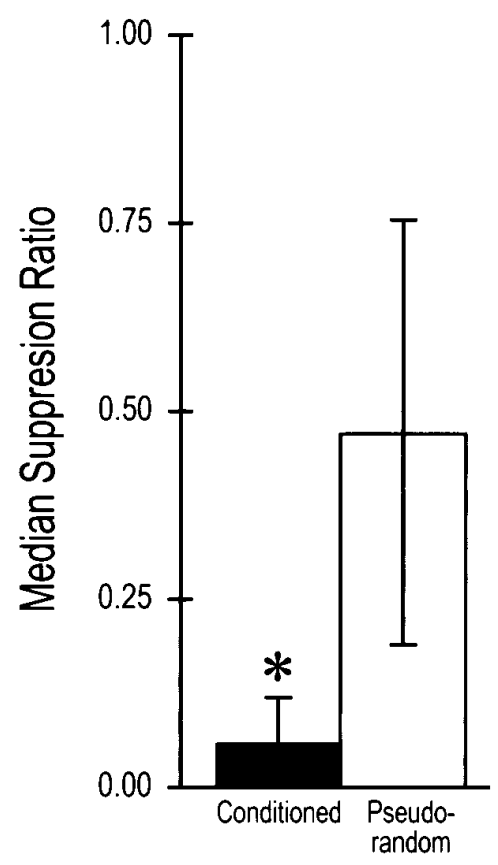

Figure 1. Median suppression ratios \pm semi-interquartile range for conditioned and pseudorandom control groups used in the analysis of IPSPs. Conditioned animals showed significant suppression of phototactic behavior compared with pseudorandom controls $\left({ }^{*} p<0.005\right)$.

type A photoreceptors. These results indicate that expression of long-term enhanced excitability in the lateral type A photoreceptor produced by conditioning is dependent on a constitutively active kinase or persistent kinase activator, whereas synaptic enhancement of identified connections from the medial B to the medial A photoreceptor in conditioned animals is not dependent on persistent $\mathrm{PKC}$ activity in the medial B photoreceptor for its expression.

A preliminary report of these results has been published previously in abstract form (Frysztak and Crow, 1996).

\section{MATERIALS AND METHODS}

Animals. Adult Hermissenda crassicornis were used in the experiments. The animals were obtained from Sea Life Supply (Sand City, CA) and maintained in closed artificial seawater (ASW) aquaria at $14^{\circ} \mathrm{C}\left( \pm 1^{\circ} \mathrm{C}\right)$ on a 12:12 light/dark cycle. Animals were fed small pieces of scallop daily. Behavioral training, testing, and electrophysiological procedures were performed during the light phase of the light/dark cycle.

Baseline test of phototactic behavior. The details of the conditioning procedures and methods for testing phototactic behavior have been described previously in detail (Crow and Alkon, 1978; Crow and Offenbach, 1983; Crow, 1985) and will be described only briefly in this report. Animals were tested before training to determine baseline latencies to initiate locomotion in response to a test light. Animals that did not respond within a $20 \mathrm{~min}$ criterion period during the pretraining measurements were not used in the conditioning experiments. Previous research has shown that the increase in the time taken by the animals to locomote into a test light can be accounted for by an increase in the latency to initiate locomotion (Crow and Offenbach, 1983). Animals were placed into glass tubes $228 \mathrm{~mm}$ long filled with ASW. A foam plug inserted through an opening confined the animal to one end of the tube. The tubes were attached by spring clips to a modified turntable enclosed in an incubator maintained at $15^{\circ} \mathrm{C}$. Animals were dark-adapted for $12 \mathrm{~min}$ before testing phototactic behavior. A light spot $\left(10^{-4}\right.$ watts $/ \mathrm{cm}^{2}$, white light) was projected onto the center of the turntable, illuminating a circular area $15-16 \mathrm{~cm}$ in diameter. The elapsed times to initiate locomotion in the presence of the test light were recorded when a Hermissenda moved between an infrared emitter and a phototransistor at the starting end of each glass tube. When the infrared beam was interrupted,
$\operatorname{PKC}(19-36)$

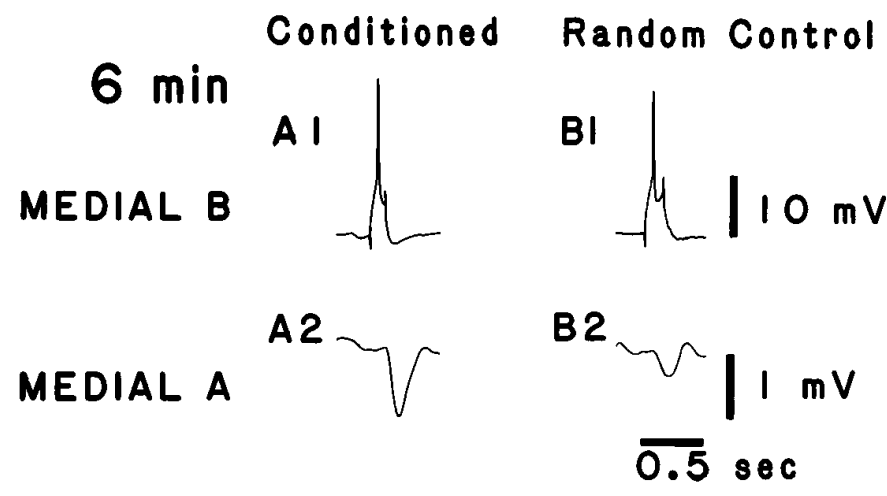

31 min $A 3$
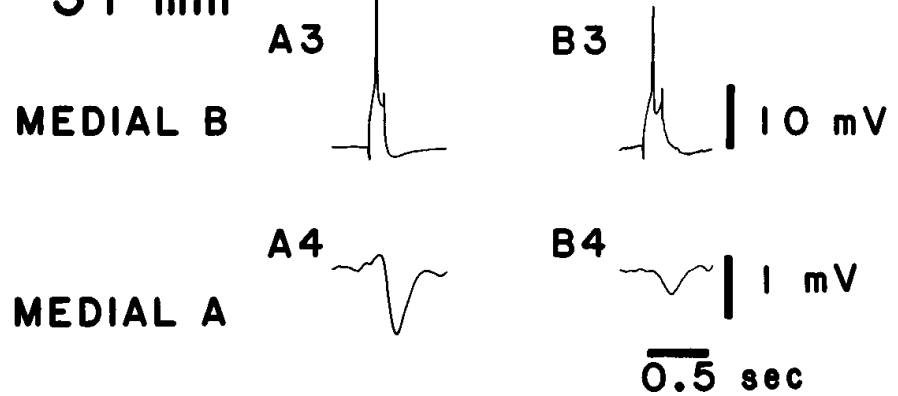

Figure 2. Inhibition of PKC activity does not block the expression of synaptic enhancement in medial type A photoreceptors of conditioned animals. $A, B$, Representative examples of spike-elicited monosynaptic IPSPs recorded from a medial type A photoreceptor in a conditioned animal $(A 2 / A 4)$ and a pseudorandom control $(B 2 / B 4)$. The corresponding medial $\mathrm{B}$ photoreceptor $(A 1 / A 3, B 1 / B 3)$ was injected with the PKC inhibitory peptide PKC(19-36), and single spikes were elicited by a brief $(150 \mathrm{msec})$ depolarizing current pulse over a time course of 31 min. The initial amplitude of the IPSP recorded in the medial type A photoreceptor from the conditioned group $(A 2)$ was larger than that recorded from the pseudorandom control (B2), but was not different substantially from the IPSP recorded from the same cell 31 min after the PKC inhibitor peptide had been injected $(A 4)$. Group data of the mean IPSP amplitudes \pm SEM at 6 min are shown in $C$. The mean IPSP amplitude in the conditioned group was significantly larger $\left({ }^{*} p<\right.$ 0.025 ) than that for the pseudorandom controls. 


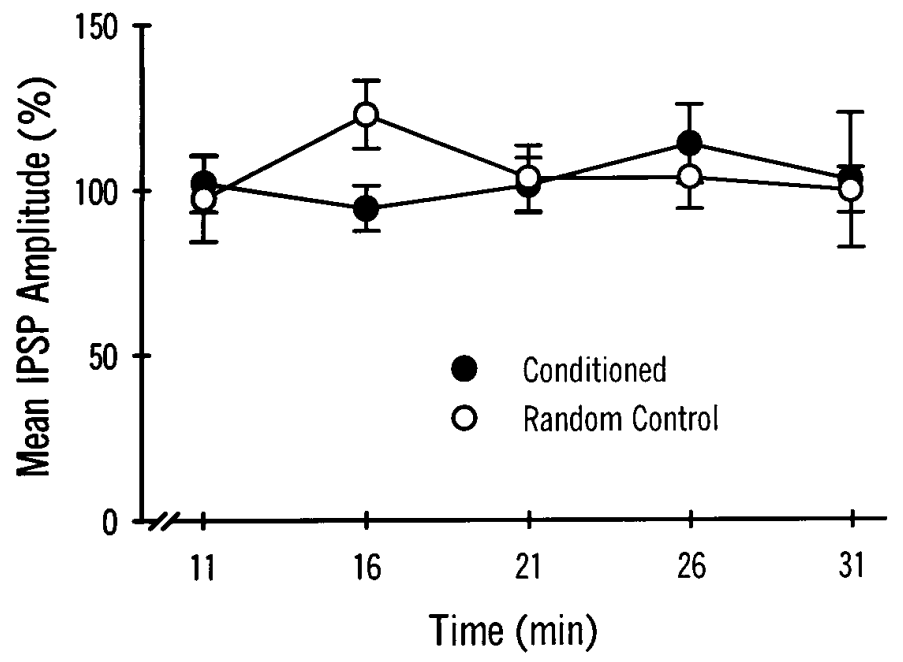

Figure 3. Group data showing the mean IPSP amplitudes (as a percentage of baseline) \pm SEM recorded from medial type A photoreceptors in conditioned animals $(n=13)$ and pseudorandom controls $(n=12)$ over time. Medial B photoreceptors were injected with the PKC inhibitor PKC(19-36). The mean percent change in IPSP amplitude for both the conditioned group and the pseudorandom controls was not significantly different over time $(11,16,21,26$, or $31 \mathrm{~min})$ from baseline values (measured at $6 \mathrm{~min}$ ) or between the two groups at any time point.

a free-running digital clock was turned off and the time recorded for later data analysis.

Conditioning procedure. After baseline measurements, animals were randomly assigned to conditioned and pseudorandom control groups. The conditioning phase consisted of 100 trials of the $10 \mathrm{sec}$ CS (light) and US (high-speed rotation) each day for 3 consecutive days. The intensity of the CS was the same as that for the test light used to establish baseline responding of phototactic behavior during the pretest condition. The pseudorandom control group received 100 trials of light and were rotation-programmed on explicitly unpaired schedules each day for 3 consecutive days. For each conditioning session, both conditioned and pseudorandom control animals were selected from the same animal shipment.

Postacquisition test. All animals received behavioral testing identical to the pretraining (baseline) test measurement for phototaxis $24 \mathrm{hr}$ after the third conditioning session. Animals that did not initiate locomotion in the presence of the CS within 20 min during the post-test received a maximum latency score. Assessment of conditioning was determined by computing suppression ratios that compared post-training phototactic behavior with pretraining test scores. The ratio is expressed as $A /(A+B)$, where $A$ represents pretraining scores and $B$ represents post-training scores. Conditioned animals exhibited behavioral suppression that was similar in magnitude to previous reports (Crow and Alkon, 1978; Crow and Offenbach, 1983; Crow, 1985). After postaquisition testing, all animals were coded so that the collection of electrophysiological data was conducted using blind experimental procedures.

Intracellular recordings. Intracellular recordings from identified medial and lateral type A and B photoreceptors were collected for conditioned and pseudorandom controls 24 or $48 \mathrm{hr}$ after the last training session. Anatomical and electrophysiological criteria were used to identify specific type A and B photoreceptors within the eye as described previously (Alkon and Fuortes, 1972).

The circumesophageal nervous systems were removed from the animals and pinned to a SYLGARD (Dow Chemical, Arlington, TN) stage in a recording chamber. The chamber was filled with ASW of the following composition (in $\mathrm{mM}$ ): $\mathrm{NaCl} 460 ; \mathrm{KCl} 10 ; \mathrm{CaCl}_{2} 10 ; \mathrm{MgCl}_{2} 55$ buffered with $10 \mathrm{~mm}$ HEPES, and brought to $\mathrm{pH} 7.46$ with $\mathrm{NaOH}$. The isolated nervous systems were incubated in a protease solution (Sigma, St. Louis, MO, $0.67 \mathrm{mg} / \mathrm{ml}, 5-7 \mathrm{~min}$ ) to facilitate microelectrode penetration of photoreceptors. Intracellular recordings were collected only from identified type A and B photoreceptors. The ASW in the recording chamber was monitored by a thermistor and held at $15^{\circ} \mathrm{C}\left( \pm 0.5^{\circ} \mathrm{C}\right)$. Illumination of the isolated nervous system was provided by a tungsten- halogen incandescent lamp attached to a fiberoptic bundle mounted underneath the recording chamber.

Spike-elicited IPSPs in the medial A-photoreceptor. The PKC inhibitor peptide PKC(19-36) (Life Technologies, Gaithersburg, MD) and the noninhibitory analog $\left[\mathrm{glu}^{27}\right] \mathrm{PKC}(19-36)$ (Life Technologies) were reconstituted in saline at a $1 \mathrm{~mm}$ concentration, aliquoted, and frozen at $-20^{\circ} \mathrm{C}$. A 0.1-1 mM concentration of either PKC(19-36) or $\left[\mathrm{glu}^{27}\right] \mathrm{PKC}(19-36)$ was used in the recording electrode in conjunction with a $4 \mathrm{~m}$ KAc solution for the medial type B photoreceptor; KAc alone was used in the electrode for the medial A photoreceptor. After impalement of an identified pair of medial type A and B photoreceptors, the nervous system was dark-adapted for $6 \mathrm{~min}$ before collection of electrophysiological data. The membrane potential of the medial A photoreceptor was maintained at $-60 \mathrm{mV}$ by the passage of extrinsic current. To minimize the possible effect of synaptic depression, type B photoreceptors were hyperpolarized to block spontaneous action potentials. Single spikes were elicited in the B photoreceptor by depolarizing current pulses of $100-150 \mathrm{msec}$ duration. The intertrial interval between stimuli for eliciting IPSPs was a minimum of $10 \mathrm{sec}$. An average of 10 IPSPs was recorded from each identified pair of medial type A and type $\mathrm{B}$ photoreceptors at each time point for both conditioned and pseudorandom controls, and an average IPSP amplitude was computed for each animal. IPSP amplitude was tested at 5 min intervals for 30-40 min after initial dark adaptation.

Bath application of $1 \mu \mathrm{M}$ serotonin (5-HT, Sigma) was used to determine the efficacy of PKC(19-36). The application of 5-HT has been shown to result in an increase in the amplitude of spike-elicited IPSPs recorded in type A photoreceptors (Schuman and Clark, 1994).

Current-elicited activity in the lateral $A$ photoreceptor. A $0.1-1 \mathrm{~mm}$ concentration of either PKC $(19-36)$ or $\left[g^{27}{ }^{27}\right] \mathrm{PKC}(19-36)$ was used in the recording electrode in conjunction with a $4 \mathrm{M} \mathrm{KAc}$ solution for lateral type A photoreceptors. After impalement of an identified lateral type A photoreceptor, the nervous system was dark-adapted for 6 min before collection of electrophysiological data. Enhanced excitability was assessed by passing depolarizing current pulses of $30 \mathrm{mV}$ from a holding potential of $-60 \mathrm{mV}$ for $10 \mathrm{sec}$ at $10 \mathrm{~min}$ intervals. An average response measured in spikes per second was determined for each animal.

Statistical analysis. Mann-Whitney $U$ tests were used to determine differences between independent groups and $t$ tests for correlated means for nonindependent groups. Because no significant differences in IPSP amplitudes were found between groups at $24 \mathrm{hr}$ compared with $48 \mathrm{hr}$ after the last training session, the data were combined for the final statistical analysis. Differences between groups at different times after the injection of PKC(19-36) were assessed with a two-way, repeated-measures ANOVA followed by pairwise multiple comparisons (Newman-Keuls method).

\section{RESULTS}

\section{PKC effects on spike-elicited IPSPs in medial type A photoreceptors}

The CS elicited significant suppression of phototactic behavior in conditioned animals $(n=13)$ as compared with pseudorandom controls $(n=12)$ (Fig. 1$)$. The behavioral results were similar to reports published previously (Crow and Alkon, 1978; Frysztak and Crow, 1993, 1994). Statistical analysis revealed that the conditioned group displayed significantly greater phototactic suppression compared with the pseudorandom control group $(U=25$, $p<0.005)$. Because the samples were drawn randomly from the populations of conditioned and pseudorandom control groups, the results are representative of the overall state of conditioning within each group.

Intracellular recordings were collected from dark-adapted pairs of identified medial type A and type B photoreceptors of conditioned and pseudorandom control animals. As reported previously, the medial B to medial A connection shows synaptic enhancement after conditioning (Frysztak and Crow, 1994). Figure 2 shows representative examples of IPSPs elicited by stimulation of a medial type $\mathrm{B}$ photoreceptor and recorded from a medial A photoreceptor in a conditioned animal and a pseudorandom control animal. The PKC inhibitor peptide PKC(19-36) was present in the recording electrode of the medial B cells. An action poten- 


\section{Control}

MEDIAL B

\section{ASW}

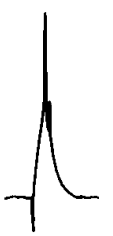

A2

MEDIAL A

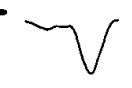

ASW+5-HT

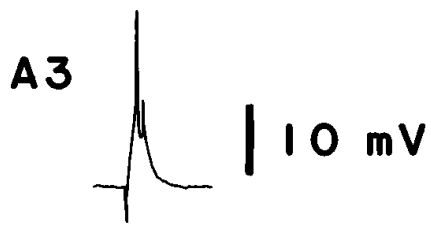

A4

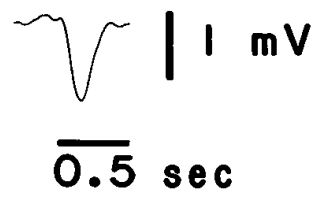

B

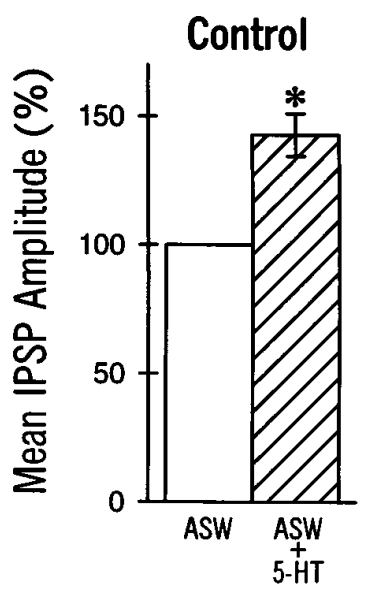

D

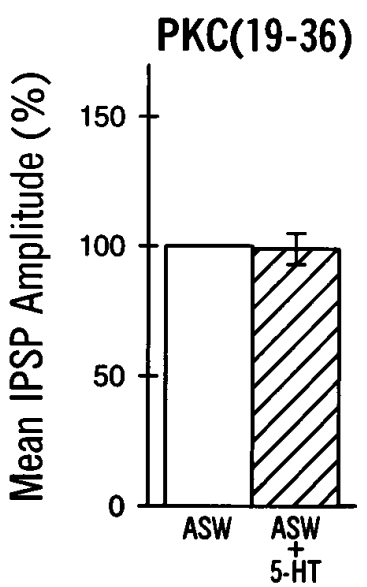

Figure 4. PKC(19-36) blocks 5-HT-induced facilitation, a PKC-dependent response. $A$, Representative examples of spike-elicited monosynaptic IPSPs recorded from medial type A photoreceptors in a control animal before $(A S W)$ and after $(A S W+5-H T)$ the bath application of serotonin $(5-H T)$. The application of serotonin results in a larger IPSP $(A 4)$ compared with the ASW alone $(A 2)$. $B$, Group data showing the mean percent increase in IPSP amplitude before $(A S W)$ and after the application of 5-HT $(A S W+5-H T)$. The application of 5-HT resulted in a significant increase in the IPSP amplitude (*ASW + 5-HT; $p<0.01)$ compared with ASW alone. $C$, Representative examples of spike-elicited monosynaptic IPSPs recorded from medial type A photoreceptors in a naive animal in the presence of the kinase inhibitor $\mathrm{PKC}(19-36)$ in the medial B photoreceptor before $(A S W)$ and after $(A S W$ $+5-H T)$ the bath application of 5-HT. The application of 5-HT did not change IPSP amplitude (C4) compared with the ASW alone (C2). $D$, Group data showing the mean percent increase in IPSP amplitude in the presence of PKC $(19-36)$ before $(A S W)$ and after $(A S W+5-H T)$ the application of 5-HT. The application of 5-HT did not increase IPSP amplitude in cells loaded with the the PKC inhibitor peptide PKC(19-36).

tial elicited in the medial $\mathrm{B}$ photoreceptor $(A 1, B 1)$ produced a monosynaptic IPSP recorded from the medial A photoreceptor $(A 2, B 2)$. The IPSP recorded from the conditioned animal $(A 2)$ is larger than the IPSP recorded from the pseudorandom control at 6 min after penetration of the photoreceptor $(B 2)$. The group data are shown in Figure $2 C$. The mean IPSP amplitude from the conditioned group $(n=13)$ is significantly larger than that of the pseudorandom control group $(n=12 ; U=40.5 ; p<0.025)$. After allowing the PKC inhibitor 31 min to diffuse into the cell, the IPSP amplitude recorded from the medial $\mathrm{A}(A 4, B 4)$ was not substantially different from the baseline value obtained at $6 \min (A 2, B 2)$ for either the conditioned or the pseudorandom control groups. The mean change in IPSP amplitude over time as a percentage of the baseline value established at $6 \mathrm{~min}$ is shown in Figure 3. As indicated by the two-way, repeated-measures ANOVA, PKC(1936) does not significantly affect IPSP amplitude over time in the medial A from either conditioned or pseudorandom control animals $\left(F_{(5,70)}=0.35\right.$, NS). These results suggest that persistent $\mathrm{PKC}$ activity in the medial $\mathrm{B}$ photoreceptor is not necessary to support the enhancement of the IPSP after conditioning in the medial B to medial type A photoreceptor connection. PKC(1936), however, may not be reaching the synaptic region in the medial B photoreceptor terminal processes. As a control to assess the efficacy of the inhibitor, we examined the effects of PKC(1936) on 5-HT-induced PKC-dependent facilitation in the B to A synaptic connection. Bath application of 5-HT has been shown to produce an enhancement of the IPSP amplitude recorded in type A photoreceptors (Schuman and Clark, 1994). As shown in Figure $4 A$, an action potential elicited in the medial type $\mathrm{B}$ photoreceptor $(A 1)$ produced a monosynaptic IPSP in the medial type $\mathrm{A}$ photoreceptor $(A 2)$ that is enhanced in amplitude after the bath application of 5-HT ( $A 4)$. The group data are shown in Figure $4 B$. The mean IPSP amplitude recorded from the medial A after the application of 5-HT $(n=4)$ was significantly larger than that recorded before in ASW $\left(t_{(3)}=5.2 ; p<0.01\right)$. In contrast, PKC(19-36) injected into the medial B photoreceptor blocked 5-HT enhancement of the IPSP in the medial A photoreceptor. The group data are shown in Figure $4 D$. The mean IPSP ampli- 


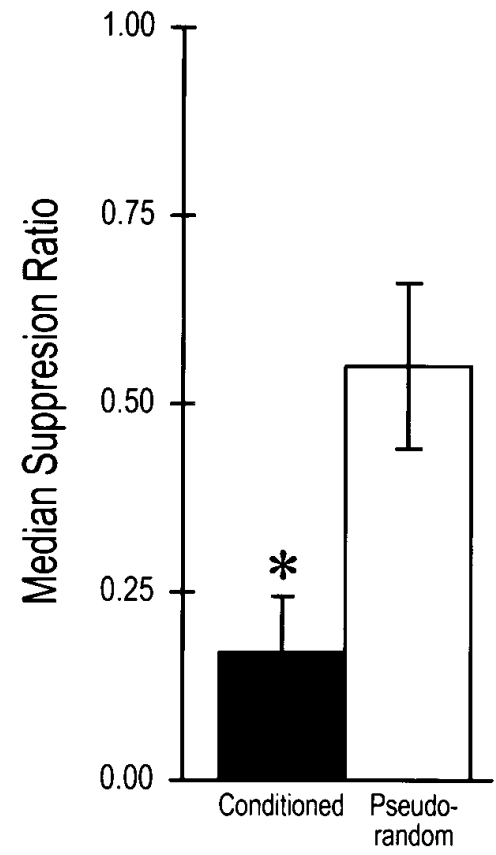

Figure 5. Median suppression ratios \pm semi-interquartile range for conditioned and pseudorandom control groups used in the analysis of excitability changes in lateral type A photoreceptors. Conditioned animals showed significant suppression of phototactic behavior compared with pseudorandom controls ( $* p<0.0001)$.

tude in the medial A after the application of 5-HT (ASW + 5-HT) in the presence of $\mathrm{PKC}(19-36)(n=4)$ was not significantly different from the IPSP without 5-HT (ASW) $\left(t_{(3)}=0.18, \mathrm{NS}\right)$. These results indicate that $\mathrm{PKC}(19-36)$ loading in the medial $\mathrm{B}$ photoreceptor is sufficient to block a PKC-dependent example of synaptic facilitation. Therefore, the absence of an effect of PKC(19-36) on conditioning-induced enhancement of IPSP amplitude suggests that $\mathrm{PKC}$ in the medial $\mathrm{B}$ photoreceptor does not play a role in the maintenance and expression of synaptic enhancement after conditioning.

\section{PKC effects on enhanced excitability in the lateral A}

The behavioral results of the post-testing of the conditioned and pseudorandom control groups that were examined for excitability changes are shown in Figure 5. The mean suppression ratios for conditioned animals $(n=15)$ and pseudorandom controls $(n=8)$ were similar to the results shown in Figure 1. Statistical analysis revealed that the conditioned group displayed significantly greater phototactic suppression compared with the pseudorandom control $(U=5, p<0.0001)$.

Intracellular recordings were collected from dark-adapted, identified lateral type A photoreceptors of conditioned and pseudorandom control animals. Conditioning results in intrinsic changes in the lateral type A photoreceptor (Farley and Alkon, 1982; Farley et al., 1990), including increases in CS-elicited spike frequency, enhanced excitability to extrinsic current (Frysztak and Crow, 1993), a reduced generator potential amplitude (Farley et al., 1990; Frysztak and Crow, 1993), and a decrease in spike frequency accommodation (Frysztak and Crow, 1993). To determine whether PKC plays a role in the maintenance and expression of these modifications, we examined the changes in excitability to extrinsic current in the presence of PKC(19-36). Figure 6 shows representative examples of spike activity elicited by a $10 \mathrm{sec}$ depolarizing extrinsic current pulse $(30 \mathrm{mV})$ in lateral type A photoreceptors from a conditioned animal and a pseudorandom control animal examined 6 and $36 \mathrm{~min}$ after penetration of the photoreceptors. Initially, the results indicated an increase in current-elicited spike activity $(A 1, B 1)$ for the cell from the conditioned animal compared with the pseudorandom control $(C 1)$. In the presence of PKC(19-36), however, spike activity in the conditioned animal was reduced substantially after $36 \mathrm{~min}(A 2)$ compared with both baseline activity at $6 \mathrm{~min}(A 1)$ and the conditioned animal that received the inactive form of the inhibitor $\left[\mathrm{glu}^{27}\right] \mathrm{PKC}(19-36)$ (B2). The PKC inhibitor did not seem to affect the spike activity in the pseudorandom control $(C 2)$. The group data showing the mean spike frequency elicited at 10 min intervals for the conditioned and pseudorandom control groups in the presence of the PKC(19-36) and the inactive form of the PKC inhibitor are shown in Figure 7. A two-way, repeated-measures ANOVA indicated that there were significant differences between the treatments $\left(F_{(2,87)}=38.7 ; p<0.0001\right)$. The interaction between treatments and time was not significant $\left(F_{(8,87)}=1.69\right.$, NS) and the main effect of time was also not significant $\left(F_{(4,87)}=\right.$ 1.05 , NS). Significant differences between groups were determined by the Newman-Keuls method. In the conditioned animals $(n=5)$, the inactive form of the PKC inhibitor, [glu $\left.{ }^{27}\right] \mathrm{PKC}(19-$ 36), did not significantly affect spike frequency over the time periods studied. Spike frequency, however, was significantly higher for the conditioned group that received the inactive form compared with pseudorandom controls $(n=8)$ at all time points studied $(q=11.52 ; p<0.05)$. In conditioned animals that received the active form of the PKC inhibitor peptide $(n=10)$, spike frequency was significantly greater than pseudorandom controls initially (6 min) $(p<0.05)$, but rapidly declined to levels not statistically different from the pseudorandom control by $16 \mathrm{~min}$. Thus, overall, the conditioned group that received the PKC inhibitor peptide was not significantly different from the pseudorandom controls ( $q=1.14$, NS). In contrast, the group that received the inactive form was significantly different from the conditioned groups that received the active inhibitor $(q=10.74 ; p<0.05)$. Initially (6 min), however, the two groups were not significantly different from each other. These results indicate that PKC contributes to the maintenance and expression of enhanced excitability observed in lateral type A photoreceptors after classical conditioning.

\section{DISCUSSION}

Studies of the CS pathway in conditioned Hermissenda by several laboratories have documented that associative learning in this system involves an enhancement of cellular excitability that is expressed in several identified cells (Crow and Alkon, 1980; Farley and Alkon, 1982; West et al., 1982; Crow, 1985; Farley et al., 1990; Frysztak and Crow, 1991; Farley and Han, 1997). Within the visual system, the medial B and lateral A photoreceptors exhibit an increase in the number of action potentials elicited by the CS after conditioning (Farley and Alkon, 1985; Frysztak and Crow, 1993). Biophysical studies of the identified sensory cells in the CS pathway have shown that the examples of enhanced excitability detected after Pavlovian conditioning are the result of modification of several diverse $\mathrm{K}^{+}$conductances (Alkon et al., 1982, 1985; Farley et al., 1990; Farley and Han, 1997). Conditioned enhancement of excitability seems to be a general characteristic of both vertebrate and invertebrate associative learning. There are now several examples of enhanced excitability detected with both associative and nonassociative learning paradigms in several differ- 


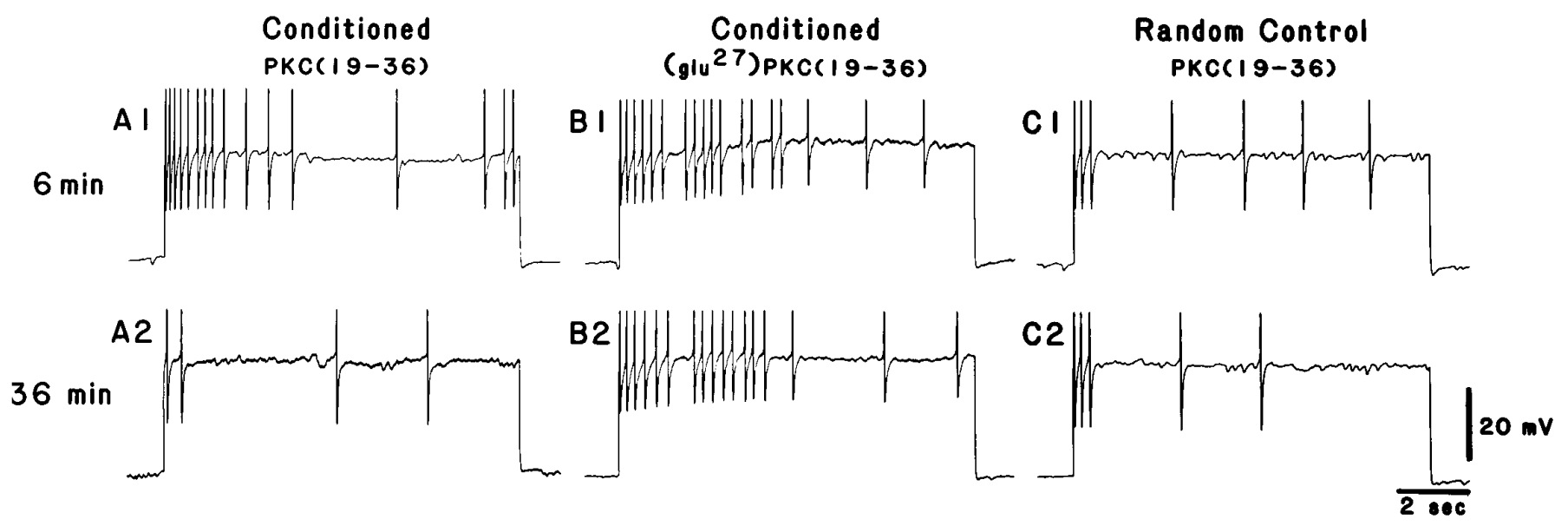

Figure 6. Representative examples of spike activity elicited by a $10 \mathrm{sec}$ depolarizing current step in lateral type A photoreceptors from conditioned animals in the presence of either PKC(19-36) or [ $\left.\mathrm{glu}^{27}\right] \mathrm{PKC}(19-36)$ and a pseudorandom control animal in the presence of PKC(19-36) at two different time points. Enhanced excitability was expressed at $6 \mathrm{~min}$ for both examples from the conditioned group ( $A 1$ and $B 1)$ compared with the example from the pseudorandom control $(C 1)$. Enhanced excitability from the conditioned group, however, was reduced substantially at 36 min $(A 2)$ compared with the initial test $(A 1)$ in the presence of the active kinase inhibitor PKC(19-36). Excitability was not affected over the same time course for the pseudorandom control ( $C 2$ vs $C 1)$ or for the conditioned group in the presence of the inactive PKC inhibitor (B2 vs $B 1)$. Note: Peaks of the action potentials are clipped by the chart recorder.

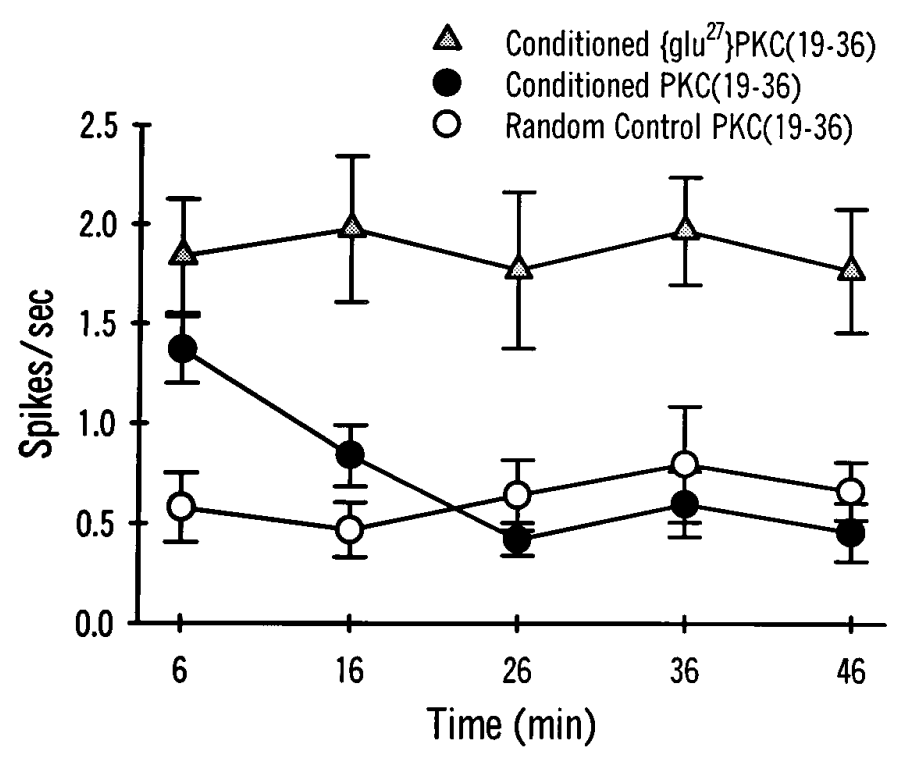

Figure 7. Group data showing the mean spike frequency during a $10 \mathrm{sec}$ depolarizing current step at different time periods recorded from lateral type A photoreceptors of conditioned (- Conditioned PKC(19-36); $n=8)$ and pseudorandom controls $(\bigcirc$ Pseudorandom Control PKC $(19-$ $36) ; n=10)$ that were impaled with electrodes containing the PKC inhibitor PKC(19-36). A separate paired group $(n=5)$ received the inactive form of the inhibitor $\left[\triangle\right.$ Conditioned $\left.\left[\mathrm{glu}^{27}\right](19-36)\right]$. The initial current step $(6 \mathrm{~min})$ elicited significantly more action potentials from lateral type A photoreceptors of conditioned animals $(\mathbf{0}, \triangle)$ compared with pseudorandom controls $(\bigcirc)$. Excitability in the conditioned group that received the active form of the inhibitor $(\mathbf{)})$, however, was reduced significantly over time. Excitability of the lateral type A photoreceptors from the conditioned group was not different significantly from pseudorandom controls at $16,26,36$, or $46 \mathrm{~min}$. The conditioned group that received the inactive form of the inhibitor $(\triangle)$ exhibited enhanced excitability over the entire 46 min period of recording.

ent invertebrate systems (for review, see Carew and Sahley, 1986; Byrne and Crow, 1992). Excitability changes in hippocampal pyramidal neurons have been detected in vitro after Pavlovian conditioning (Moyer et al., 1996; Thompson et al., 1996). In addition to enhanced excitability as a correlate of Pavlovian conditioning, enhancement of synaptic strength has also been observed after conditioning in Hermissenda (Frysztak and Crow, 1994). The present study shows that these two correlates of associative learning, enhanced excitability, and enhanced synaptic strength, may involve two different mechanisms for their expression. We have provided evidence that enhanced excitability of lateral A photoreceptors of conditioned animals can be reversed by the intracellular injection of the PKC inhibitor PKC(19-36). These results, thus, provide evidence that a constitutively active form of PKC or a persistent activator of PKC supports the long-term excitability of lateral A photoreceptors in conditioned animals. In contrast, the same PKC inhibitors injected into B photoreceptors did not reverse the enhancement of IPSPs recorded from medial A photoreceptors of conditioned animals, suggesting that a different mechanism supports long-term synaptic enhancement if the site of the plasticity is presynaptic.

\section{Role of PKC in the expression of cellular correlates}

PKC has been proposed to contribute to several examples of cellular and synaptic plasticity in both vertebrates and invertebrates (Akers et al., 1986; Farley and Auerbach, 1986; Neary et al., 1986; Alkon et al., 1988; Malinow et al., 1989; Braha et al., 1990; Matzel et al., 1990; Sacktor and Schwartz, 1990; Crow et al., 1991; Sugita et al., 1992). In Hermissenda, PKC inhibitors have been reported to block the induction of short-term plasticity (Matzel et al., 1990; Crow et al., 1991; Crow and Forrester, 1993) and reverse the expression of established plasticity in conditioned animals (Farley and Schuman, 1991). Moreover, downregulation of PKC has also been shown to be effective in blocking the induction of short-term plasticity (Crow et al., 1991; Crow and Forrester, 1993). Several studies of type B photoreceptors have shown that injection of PKC and activation of $\mathrm{PKC}$ by phorbol esters or diacylglycerol reduces several of the $\mathrm{K}^{+}$conductances that have been implicated in supporting enhanced excitability produced by conditioning (Farley and Auerbach, 1986; Alkon et al., 1988). Taken collectively, the evidence indicates that PKC activity plays a major role in both the induction of short-term plasticity and the long-term enhanced excitability of conditioned animals. Our re- 
sults are therefore consistent with the hypothesis that either a long-lived activator or a constitutively active kinase is important for the expression of enhanced excitability detected in lateral $\mathrm{A}$ photoreceptors after conditioning. It was proposed previously that a similar mechanism underlies the enhanced excitability of type B photoreceptors in conditioned animals (Farley and Schuman, 1991). Our findings, however, indicate that a different mechanism must contribute to the enhanced synaptic strength observed at the medial B to medial A connection of conditioned animals if the plasticity is presynaptic. An alternative hypothesis is that the modification of IPSP amplitude is postsynaptic and thus localized to the medial A photoreceptor. A postsynaptic increase in input resistance that would result in larger IPSPs, however, is not consistent with work published previously showing that the input resistance of type A photoreceptors is reduced in conditioned animals and that outward $\mathrm{K}^{+}$currents are enhanced (Farley et al., 1990; Farley and Han, 1997). A change in the number or density of receptor binding sites on the postsynaptic membrane would be consistent with a postsynaptic locus for enhancement and has not been ruled out by research published previously. It could also be argued that the modification in the medial $\mathrm{B}$ photoreceptors that support enhanced synaptic strength after conditioning are not accessible to the actions of the peptide inhibitor. We have shown, however, that a PKC-dependent example of synaptic plasticity, 5-HT-induced facilitation, can be blocked by the intracellular injection of the PKC inhibitor PKC(19-36) into the medial B photoreceptors. Thus, it seems unlikely that the inhibitor would not have access to the subcellular domain important in the expression of plasticity. In addition, these results provide the first direct evidence that 5-HT-induced facilitation of the connection between the medial B and medial A photoreceptor is presynaptic. An additional implication of our results is that conditioning results in changes in synaptic strength that must involve a different mechanism from the PKC-dependent mechanism of 5-HT-induced synaptic facilitation.

\section{Localization of cellular correlates of conditioning}

There is now considerable evidence to indicate that conditioning produces cellular and synaptic modifications at multiple loci in the Hermissenda nervous system. Changes have been detected in different identified B photoreceptors as well as in both identified type A photoreceptors (Crow, 1988; Frysztak and Crow, 1993). In addition, correlates have been investigated in the pedal neurons that receive synaptic input from photoreceptors in the CS pathway (Hodgson and Crow, 1991). Multiple sites of synaptic plasticity have also been identified in Aplysia after sensitization procedures (Frost et al., 1988; Trudeau and Castellucci, 1993; Lee et al., 1995). Results published previously and our present findings show that conditioning results in enhanced excitability intrinsic to different identified cell types within the CS pathway and enhancement of a specific synaptic connection between cells in the CS pathway (Frysztak and Crow, 1993). Therefore, both synaptic enhancement and enhanced excitability are expressed in conditioned animals within and between identified neurons in the pathway supporting the CS and may involve different subcellular mechanisms. In addition, there are several potential loci for plasticity in the optic ganglia and interneuronal pool that receive synaptic input from the CS pathway and project to motor neurons responsible for the generation of the conditioned response.

\section{REFERENCES}

Akers RF, Lovinger DM, Colley PA, Linden DJ, Routenberg A (1986) Translocation of protein kinase $\mathrm{C}$ activity may mediate hippocampal long-term potentiation. Science 231:587-589.

Alkon DL, Fuortes MGF (1972) Responses of photoreceptors in Hermissenda. J Gen Physiol 60:631-649.

Alkon DL, Lederhendler I, Shoukimas JJ (1982) Primary changes of membrane currents during retention of associative learning. Science 215:693-695.

Alkon DL, Sakakibara M, Forman R, Harrigan J, Lederhendler I, Farley $\mathrm{J}$ (1985) Reduction of two voltage-dependent $\mathrm{K}^{+}$currents mediates retention of a learned association. Behav Neurol Biol 44:278-300.

Alkon DL, Naito S, Kubota M, Chen C, Bank B, Smallwood J, Gallant P, Rasmussen H (1988) Regulation of Hermissenda $\mathrm{K}^{+}$channels by cytoplasmic and membrane-associated C-kinase. J Neurochem 51:903-917.

Braha O, Dale N, Hochner B, Klein M, Abrams TW, Kandel ER (1990) Second messengers involved in the two processes of presynaptic facilitation that contribute to sensitization and dishabituation in Aplysia sensory neurons. Proc Natl Acad Sci USA 87:2040-2044.

Byrne JH, Crow T (1992) Examples of mechanistic analyses of learning and memory in invertebrates. In: Learning and memory (Martinez JL, Kesner RP, eds), pp 329-358. New York: Academic.

Carew TJ, Sahley CL (1986) Invertebrate learning and memory: from behavior to molecules. Annu Rev Neurosci 9:435-487.

Crow T (1985) Conditioned modification of phototactic behavior in Hermissenda. II. Differential adaptation of B-photoreceptors. J Neurosci 5:215-223.

Crow T (1988) Cellular and molecular analysis of associative learning and memory in Hermissenda. Trends Neurosci 11:136-142.

Crow T, Alkon DL (1978) Retention of an associative behavioral change in Hermissenda. Science 201:1239-1241.

Crow T, Alkon DL (1980) Associative behavioral modification in Hermissenda: cellular correlates. Science 209:412-414.

Crow T, Forrester J (1993) Down-regulation of protein kinase C and kinase inhibitors dissociate short- and long-term enhancement produced by one-trial conditioning of Hermissenda. J Neurophysiol 69:636-641.

Crow T, Offenbach N (1983) Modification of the initiation of locomotion in Hermissenda: behavioral analysis. Brain Res 271:301-310.

Crow T, Forrester J, Williams M, Waxham N, Neary J (1991) Downregulation of protein kinase $\mathrm{C}$ blocks 5-HT-induced enhancement in Hermissenda B photoreceptors. Neurosci Lett 12:107-110.

Farley J, Alkon DL (1982) Associative neural and behavioral change in Hermissenda: consequences of nervous system orientation for light- and pairing-specificity. J Neurophysiol 48:785-807.

Farley J, Alkon DL (1985) Cellular mechanisms of learning, memory, and information storage. Annu Rev Psychol 36:419-464.

Farley J, Auerbach S (1986) Protein kinase C activation induces conductance changes in Hermissenda photoreceptors like those seen in associative learning. Nature 319:220-223.

Farley J, Schuman E (1991) Protein kinase C inhibitors prevent induction and continued expression of cell memory in Hermissenda type B photoreceptors. Proc Natl Acad Sci USA 88:2016-2020.

Farley J, Han Y (1997) Ionic basis of learning-correlated excitability changes in Hermissenda type A photoreceptors. J Neurophysiol 73, in press.

Farley J, Richards WG, Grover LM (1990) Associative learning changes intrinsic to Hermissenda type A-photoreceptors. Behav Neurosci 104:135-152.

Frost WN, Clark GA, Kandel ER (1988) Parallel processing of shortterm memory for sensitization in Aplysia. J Neurobiol 19:297-234.

Frysztak RJ, Crow T (1993) Differential expression of correlates of classical conditioning in identified medial and lateral type A photoreceptors of Hermissenda. J Neurosci 13:2889-2897.

Frysztak RJ, Crow T (1994) Enhancement of type B- and type A-photoreceptor inhibitory connections in conditioned Hermissenda. J Neurosci 14:1245-1250.

Frysztak RJ, Crow T (1996) Neural correlates intrinsic to pre-synaptic and post-synaptic neurons in the CS pathway of conditioned Hermissenda. Soc Neurosci Abstr 22:11.

Hodgson TM, Crow T (1991) Characterization of 4 light-responsive putative motor neurons in the pedal ganglia of Hermissenda crassicornis. Brain Res 557:255-264. 
Lee WL, Aguirre M, Cleary LJ, Byrne JH (1995) Cellular correlates of long-term sensitization in Aplysia. Soc Neurosci Abstr 21:1680.

Malinow R, Schulman H, Tsien RW (1989) Inhibition of post-synaptic PKC or CaMKII blocks induction but not expression of LTP. Science 245:862-866.

Matzel LD, Lederhendler II, Alkon DL (1990) Regulation of short-term associative memory by calcium-dependent protein kinase. J Neurosci 10:2300-2307.

Moyer JR, Thompson LT, Disterhoft JF (1996) Trace eyeblink conditioning increases CA1 excitability in a transient and learning-specific manner. J Neurosci 16:5536-5546.

Neary JT, Naito S, DeWeer A, Alkon DL (1986) $\mathrm{Ca}^{2+} /$ diacylglycerolactivated, phospholipid-dependent protein kinase in the Hermissenda CNS. J Neurochem 47:1405-1411.

Sacktor TC, Schwartz JH (1990) Sensitizing stimuli cause translocation of protein kinase C in Aplysia sensory neurons. Proc Natl Acad Sci USA 87:2036-2039.

Schultz LM, Clark GA (1995) GABA-induced facilitation at type B to A photoreceptor synapses in Hermissenda. Soc Neurosci Abstr 21:1679.
Schuman EM, Clark GA (1994) Synaptic facilitation at connections of Hermissenda type B-photoreceptors. J Neurosci 14:1613-1622.

Sugita S, Goldsmith JR, Baxter DA, Byrne JH (1992) Involvement of protein kinase $\mathrm{C}$ in serotonin-induced spike broadening and synaptic facilitation in sensorimotor connections of Aplysia. J Neurophysiol 68:643-651.

Thompson LT, Moyer JR, Disterhoft JF (1996) Transient changes in excitability of rabbit CA3 neurons with a time-course appropriate to support memory consolidation. J Neurophysiol 76:1836-1849.

Trudeau LE, Castellucci VF (1993) Sensitization of the gill and siphon withdrawal reflex of Aplysia: multiple sites of change in the neuronal network. J Neurophysiol 70:1210-1220.

West A, Barnes ES, Alkon DL (1982) Primary changes of voltage responses during retention of associative learning. J Neurophysiol 48:1243-1255.

Yamoah EN, Crow T (1996) Protein kinase and G-protein regulation of $\mathrm{Ca}^{2+}$ currents in Hermissenda photoreceptors by 5-HT and GABA. J Neurosci 16:4799-4809. 